\title{
FACTORS INFLUENCING THE STRESS DURING MENSTRUATION AMONG ADOLESCENT GIRLS
}

\author{
*Prof. C. Kavitha, **Dr. S. Jayalakshmi \& ***Dr. John William Felix
}

\begin{abstract}
Adolescence is the unique phase of life during which a child goes through tremendous physical, emotional and social changes it leads to a lot of problems because of psychological and physical discomfort. Most of them do not feel comfortable and confident to discuss their problems with their parents. The main challenges are managing menstruation. This article is to assess the Factors influencing the stress during menstruation among adolescent girls. After formal permission and ethical clearance, 490 samples were selected based on the non probability purposive technique. The result showed that the factors influencing the stress during menstruation are fatigue, family history and number of days of bleeding.
\end{abstract}

\section{Key word : Adolescent girls, menstruation, stress and its factors.}

\section{Introduction}

The adolescent period is vulnerable period due to absence of proper guidance and counseling. However, within an integrated approach, health services can play an important role in helping adolescents to stay healthy and to complete their journey to adulthood; supporting young people who are looking for a route to good health, treating those who are ill, injured or troubled and reaching out to those who are at risk. Each adolescent has to resolve her own identity crisis. Parent, teachers and school health nurse can offer their support and help them in the process.

\section{Statement of the problem}

A study to assess the factors influencing stress during menstruation among adolescent girls in selected schools at Salem, Tamil Nadu, India.

\section{Objectives}

1. To find the level of stress during menstruation among adolescent girls.
2. To assess the factors influencing the stress during menstruation among adolescent girls.

\section{Methodology}

A quantitative approach with descriptive cross sectional study design was used. The study was conducted in selected schools at Salem. Formal permission was received from the Chief Educational Officer and school Principals by submitting the proposal of the study. Non probability purposive sampling technique was adopted for sample selection. Totally 497 samples were surveyed and 490 samples had stress during menstruation in any one aspects related to the menstruation. Thus the sample size was 490 . The data were gathered by using profoma to assess the base line information and adolescent stress scale to assess the level of stress.

Result

The result indicated that out of 490 samples $263(53.7 \%)$ had mild stress, 163 (33.3\%) had moderate stress and 64 (13.1\%) had severe stress during menstruation. The chi- 
square value shows that there is a significant association in the level of stress among adolescent girls and their number of days of bleeding $\left(X^{2}=38.79\right)$, amount of bleeding $\left(X^{2}=\right.$ 31.29), Family history of dysmenorrhoea $\left(X^{2}=\right.$ 50.16), Abdomen pain $\left(X^{2}=128.98\right)$, Fatigue $\left(X^{2}=93.89\right)$, thigh pain $\left(X^{2}=64.98\right)$, Back ache $\left(X^{2}=39.96\right)$, Head ache $\left(X^{2}=58.53\right)$, vomiting $\left(X^{2}=33.24\right)$ and giddiness $\left(X^{2}=32.61\right)$ at $\mathrm{p}<0.001$.
The Classification And Regression Tree (CART) model has been applied to find out the most significant variable associated with stress among the demographic and menstrual variable. The main advantage of this CART model is to get the interaction relationship within the selected variables. The result of the CART model is shown in figure 1 . Here demographic and menstrual variables are involved to identify the most influencing factor for stress during the menstruation.

\section{STRESSPRE}

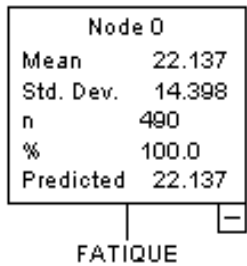

Adj. P-value $=0.000, F=52.330$,

$d f 1=3, d f 2=486$

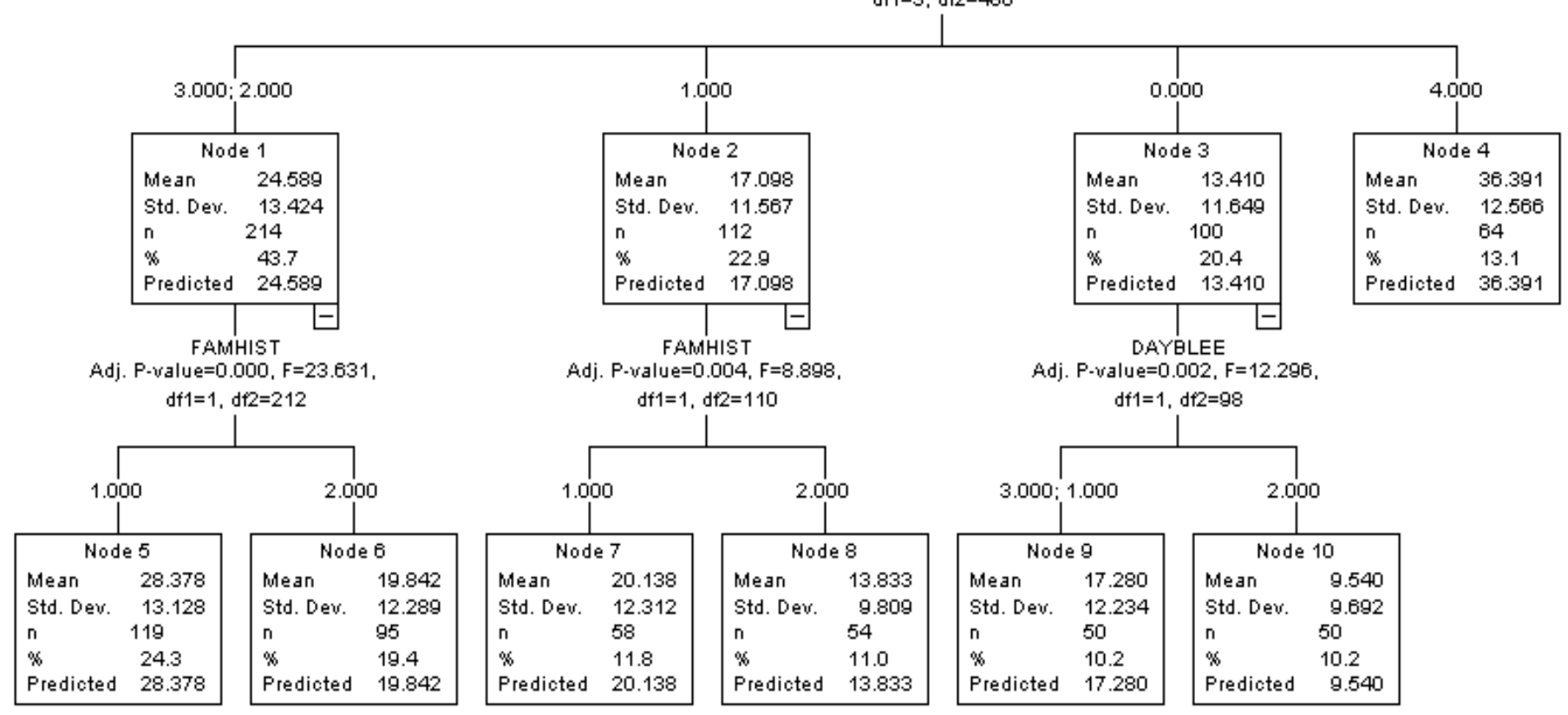

Figure 1. Classification and regression tree for predicting the influencing factors of stress during menstruation among adolescent girls. 
The above figure showed that fatigue, family history and number of days of bleeding are the common factors involved in stress. Among this, fatigue has been identified as a most significant variable than the other variables. If the adolescent has severe fatigue the level of stress is also high during menstruation. If they have family history of primary dysmenorrhoea, the level of stress is more than those who do not have family history. Further if the girls had mild fatigue, the number of days of bleeding has an influence on their level of stress.

\section{CONCLUSION}

The result revealed that there is an association in the level of stress during menstruation and above said variables. Thus the researcher concluded based on the CART model that the intensity of fatigue increases, the level of stress also increases. Also the family history and number of days of bleeding has been identified as influencing factor for the stress among the adolescent girls during menstruation. So Nurses play an important role of the nurses to educate and help them to overcome the stress among the adolescent girls.

\section{Reference:}

Dr. Aravind Dubey, Health for Adolescent girls, retrievedfromwww.Vigyanprasar.gov.in/radio serials/Health for Adolescent girls.pdf.

L Wang, $\mathrm{X}$ Wang, W Wang, $\mathrm{C}$ Chen, a Ronnennberg, W Guang, A Huang, Z Fang, T Zang And X Xu. (2004). Stress and Dysmenorrhoea: A population based perspective study. Occupational environment Medicine, 61(12), 1021-1026. DOI: 10.113/oem.2003.012302.

Mariam kabirian, Zahara Abedian, Seyad Reza Mazlom, Behroz Mahram. (2011). Self management in primary dysmenorrhoea: Toward Evidence based Education. Life science journal, 8() 2, retrieved from www. Lifesciencesite.com.

Polit \& Hungler B.P. Nursing Research Principles and method. Philadelphia; J.P. Lipincott company.

Swarna Rekha Bhat.(2009). Achars Text Book of Pediatrics. $\left(4^{\text {th }}\right.$ edi). Hydrabad, Universities press.

Hennekens CH, Buring JE. Epidemiology in Medicine, Lippincott Williams \& Wilkins, 1987. 